\title{
PEMENTASAN JRO GEDE PANEMBAHAN SAKTI DI DESA GUBUG PERSPEKTIF KOMUNIKASI TRANSENDENTAL
}

\author{
Ni Komang Susani ${ }^{a, 1}$ \\ I Nengah Duija ${ }^{a}$ \\ Made Sri Putri Purnamawati ${ }^{\mathrm{a}}$ \\ a Universitas Hindu Negeri I Gusti Bagus Sugriwa Denpasar \\ ${ }^{1}$ Corresponding Author, email: susankomang@gmail.com (Susani)
}

ARTICLE INFO

\section{Article history:}

Received: 13-01-2021

Revised: 27-02-2021

Accepted: 19-03-2021

Published: 31-03-2021

Keywords:

Staging, Jro Gede

Panembahan Sakti,

Transcendental

Communication
ABSTRACT

Jro Gede Panembahan Sakti staging in Gubug Village, Tabanan District is a dance performance that uses the symbol of a form of Barong Landung or what is called Jro Gede Panembahan Sakti. The issues to be discussed include: (1) What is the process of staging Jro Gede Panembahan Sakti in Gubug Village, Tabanan District, Tabanan? (2) What elements of communication are contained in the performance of Jro Gede Panembahan Sakti in Gubug Village, Tabanan District, Tabanan Regency? (3) What are the communication implications arising in the performance of JroGedePanembahanSakti in Gubug Village, Tabanan District, Tabanan Regency? Analyze the problem formulation : Aesthetic by Djelantik, Interersonal Communication by Burhan Bungin, and The Dependency Theory of Mass Communication Effects by Ardianto. The methods used to collect data are: observation, interviews, documentation and literature. The results of the study show that (1) the process of implementing Jro Gede Panembahan Sakti in Gubug Village, Tabanan District, Tabanan Regency, namely: History of Jro Gede Panembahan Sakti where it began during Majapahit government and the entry of other religions that were not Hindu in Majapahit and at that time Bhatara Dalem Majapahit left Majapahit, the form of prerai, gambelan used, clothing, offerings and the process of staging Jro Gede Panembahan Sakti, at the initial stage of preparation, implementation and closing stages. (2) The elements of communication contained in the performance of Jro Gede Panembahan Sakri in the village of Gubug, namely: Communications, messages, media, communicants, and feedback, (3) Implications of Communication in the Staging of Jro Gede Panembahan Sakti in Gubug Village, namely: knowledge (knowledge about staging, and learning of Hinduism), Tri Hita Karana implications and religious implication.

\section{PENDAHULUAN}

Keyakinana masyarakat di Desa Gubug tentang Pementasan Jro Gede Panembahan sakti merupakan sesuwunan yang berwujud Barong Landung, dan merupakan tarian ritual yang sangat disakralkan oleh masyarakat di Desa Gubug. Pementasan Jro Gede Panembahan Sakti adalah salah satu rangkaian pelaksanaan upacara Dewa Yadnya pada saat piodalan di Pura Panembahan Sakti Dalem Majapahit sebagai 
pemuput Karya, Pementasan Jro Gede Panembahan Sakti diyakiti oleh masyarakat Gubug bisa menghilangkan wabah penyakit dan hal-hal yang bersifat leteh tersebut.

Pementasan Jro Gede Panembahan Sakti dilaksanakan pada Hari Raya Kuningan tepatnya pada Saniscara Kliwon Wuku Kuningan, kenapa dilaksanakan pada saat Hari Raya Kuningan karena, pada saat Hari Raya Kuningan bertepatan dengan piodalan di Pura Panembahan Sakti Dalem Majapahit. Masyarakat di Desa Gubug sangat meyakini sesuwunan yang berupa Barong Landung memberi kesejahteraan di Desa Gubug. Keyakinan yang dimiliki oleh masyarakat di Desa Gubug membuktikan bahwa masyarakat DesaGubug merupakan masyarakat yang religius, karena dari keyakinan dalam Pementasan Jro Gede Panembahan Sakti tersebut berpengaruh terhadap kesuksesan pelaksanaan upacara yang dilaksanakan di Pura Panembahan Sakti Dalem Majapahit Desa Gubug. Apabila pementasan Jro Gede Panembahan Sakti tidak dipetaskan maka, pelaksanaan piodalan dianggap belum puput (selesai) dan bisa menyebabkan terjadinya suatu bencana pada masyarakat di Desa Gubug.Keunikan dari Pementasan Jro Gede Panembahan Sakti di Desa Gubug adalah Jro Gede Panembahan Sakti merupakan sesuwunan yang berbentuk barong landung, dimana biasanya barong landung ada dua yaitu barong landung lanang dan barong landung istri, tetapi di Pura Panembahan Sakti Dalem Majapahit di Desa Gubug terdapat hanya satu yaitu Barong Landung Lanang (laki-laki) yang diberi nama Jro Gede Panembahan Sakti. Sedangkan, keunikan penelitian ini dalam kajian komunikasi adalah akan mampu mengungkap berbagai macam kebingungan masyarakat terhadap keberadaan Jro Gede Panembahan Sakti yang berbentuk barong landung lanang, hal ini sangat perlu dikaji mendalam dengan pendekatan komunikasi Transendental agar dapat mengetahui proses komunikasi, unsur komunikasi dan implikasi komunikasi Jro Gede
Panembahan Sakti di Desa Gubug Kecamatan Tabanan Kabupaten Tabanan.

Kesenjangan yang terjadi adalah makna dan esensi pementasan Jro Gede Panembahan Sakti belum banyak diketahui oleh masyarakat, paham anak mule keto masih banyak dipegang teguh oleh masyarakat khususnya generasi muda. Kajian komunikasi Transendental terhadap pementasan Jro Gede Panembahan Sakti, agar masyarakat memiliki pemahaman yang seimbang antara aturan yang mendasari dan juga implementasi upacara tersebut, dan menciptakan kecintaan generasi muda terhadap tradisi unik di wilayah Desa Gubug Kecamatan Tabanan Kabupaten Tabanan.Pementasan Jro Gede Panembahan Sakti diharapkan masyarakat di Desa Gubug bisa terhindar dari kesengsaraan dian masyarakat di Desa Gubug bisa tetap mempertahankan Pementasan Jro Gede Panembahan Sakti ini. Tetapi masyarakat di Desa Gubug belum semua yang memahami tentang pementasan Jro Gede Panembahan Sakti, dari penomena ini peneliti ingin mengungkap semua kenyataan yang ada dilapangan, supaya masyarakat paham akan Pementasan Jro Gede Panembahan Sakti.

\section{METODE PENELITIAN}

Metode yang digunakan dalam penelitian ini adalah kualitatif dengan berfokus pada observational case participation observation yaitu peneliti ikut dalam pelaksanaan objek yang diobservasi sekaligus berkedudukan sebagai pengamat dengan wilayah/ruang lingkup observasi yang telah dibatasi secara tegas sesuai dengan masalah dan tujuan penelitian. Sempel yang digunakan dalam penelitian ini adalah teknik purposive sampling.Teknik prurposive sampling adalah penentuan informan dipilih dengan mempertimbangkan pengetahuan mereka tentang masalah yang berkaitan dengan "Pementasan Jro Gede Panembahan Sakti di Desa Gubug Kecamatan Tabanan Kabupaten Tabanan (Perspektif Komunikasi Transendental". Penelitian ini menjelaskan dan mendeskripsikan 
peristiwa, aktivitas, kepercayaan, sikap, social dan pemikiran orang lain baik secara individual dan kelompok. Pengumulan data, peneliti menggunakan teknik obervasi, wawancara mendalam, studi dokumentasi dan partisipasi aktif di lokasi penelitian. Analisis data kualitatif dilakukan dengan analisis non statistic atau deskriptif.

\section{HASIL DAN PEMBAHASAN}

\section{Proses Pementasan Jro Gede Panembahan Sakti di Desa Gubug Kecamatan Tabanan Kabupaten Tabanan}

Pada dasarnya setiap kegiatan upacara yajna dan tradisi bagi umat Hindu di Bali memiliki proses sebagai suatu kesatuan yang mampu memberikan gambaran tentang sarana, tempat dan waktu suatu tradisi itu dilaksanakan.Dalam hal ini Pementasan Jro Gede Panembahan Sakti di Desa Gubug Kecamatan Tabanan juga memiliki prosesi atau sesuai dengan kepercayaan umat Hindu di Desa Gubug. Sesuai dengan teori estetika menurut Djelantik (1999 :9) menjelaskan bahwa estetika adalah suatu cabang ilmu yang mempelajari segala sesuatu yang berkaitan dengan keindahan dan semua aspek dari apa yang disebut keindahan. Keindahan Pementasan Jro Gede Panembahan Sakti di Desa Gubug mengandung makna estetika. Pementasan Jro Gede Panembahan Sakti menampilkan banyak unsur keindahan, antara lain tampak dari gerakan yang ditampilkan secara harmonis, serasi dan menyatu dengan gambelan yang mengiringi pementasan Jro Gede Panembahan Sakti. Gerakan yang dilakukan pada saat pementasan Jro Gede Panembahan Sakti memiliki kekhasan tersendiri, begitu pula bentuk dari prerai Jro gede Panembahan Sakti yang memiliki unsur keindahan dari seni rupa, busana dan properti yang digunakan pada saat pemetasan Jro Gede Panembahan Sakti sangat serasi dan menampilkan keindahan. Lantunan suara gambelan serta gerakan pada Jro Gede Panembahan Sakti selalu sejalan dan beriringan hingga membuat orang betul-betul menikmati rasa keindahan dan kesakralan Barong Landung atau disebut dengan Jro Gede Panembahan Sakti. Proses pelaksanaan pementasan Jro Gede Panembahan Sakti di Desa Gubug Kecamatan Tabanan Kabupaten Tabanan dilaksanakan dengan beberapa tahapan yaitu : (1) waktu dan tempat pelaksanaan, (2) tahap awal persiapan, (3) tahap pelaksanaan dan (3) tahap akhir.

\section{Unsur-unsur Komunikasi yang Terkandung dalam Pelaksanaan Pementasan Jro Gede Panembahan Sakti di Desa Gubug Kecamatan Tabanan Kabupaten Tabanan}

Sesuai dengan teori komunikasi interpersonal yang dijelaskan oleh Arni Muhammad (2009 : 159) mendefinisikan "Komunikasi Interpersonal" adalah proses pertukaran informasi di antara seseorang dengan paling kurang seorang lainnya atau biasanya diantara dua orang yang dapat langsung diketahui balikannya. Dengan bertambahnya orang yang terlibat dalam komunikasi, menjadi bertambahlah persepsi dalam kejadian komunikasi sehingga bertambah komplekslah komunikasi tersebut. Inti Komunikasi interpersonal dalam Pementasan Jro Gede Panembahan Sakti bagi masyarakat di Desa Gubug yakni dari komunikasi yang terjadi antara pemangku di Pura Panembahan Sakti dengan sesuwunan di Pura Panembahan Sakti yaitu berupa pawisik yang diberikan Jro Gede Panembahan Sakti untuk melaksanakan Pementasan Jro Gede Panembahan Sakti pada saat piodalan di Pura Panembahan Sakti Dalem Majapahit dan dilanjutkan dengan komunikasi yang dilakukan dengan masayrakat agar pelaksanaan suatu kegiatan bisa berjalan dengan lancar. Komunikasi interpersonal yang terjadi pada saat pementasan Jro Gede Panembahan Sakti bagi masyarakat yakni bisa memaknai konsep menyamabraya karenan semua anggota masyarakat adalah saudara, sehingga bergotong royong menyukseskan pementasan Jro Gede Panembahan Sakti. Dengan demikian dapat 
diketahui bahwa komunikasi terdiri dari beberapa unsur yang mempengaruhi seperti ; komunikator, pesan, media, komunikan dan kilas balik.

\section{Implikasi Komunikasi yang Ditimbulkan dalam Pementasan Jro Gede Panembahan Sakti di Desa Gubug Kecamatan Tabanan Kabupaten Tabanan}

Penggunaan tarian dalam sistem pemujaan sebagaimana dikenal dalam lingkungan umat Hindu di Bali bukan sebagai unsur pemeriah ritual, tetai digunakan dalam mengiringi ritual berfungsi sebagai simbol metafisika yang mewakili hal yang transendetal. Sesuai dengan teori Ritual yang dikemukanan oleh Abdullah (2008: 6) ritual sebagai suatu pemadatan nilai kelompok dan komunikasi dapat ditanggapi sebagai sebuah pernyataan tentang prioritas nilai atau hal-hal yang dianggap ideal dan penting dalam suatu masyarakat. Lebih lanjut dikatakan bahwa ritual menjadi jabatan bagi tujuan pemahaman dunia ideal suatu masyarakat. Asumsi filosofi dari teori ritus adalah manusia sebagai homo religious. Ritus merupakan suatu upaya manusia untuk mencari hubungan dengan dunia transedental dengan tujuan untuk mendapatkan keselamatan, ketentraman dan sekaligus menambah kelestarian kosmos, pelaksanaan ritualisasi merupakan upacara keagamaan yang paling umum di dunia yang melambangkan kesatuan mistis dan sosial dari mereka yang ikut hadir di dalamnya (Geertz, 1992 : 13).

Pementasan Jro Gede panembahan sakti memiliki tujuan bersama bagi Desa Gubug, sehingga terjadinya perubahan dalam kehidupan masyarakat di Desa Gubug akan dapat tercapai apabila diawali dengan menjaga keharmonisan hubungan manusia dengan Tuhannya. Jika manusia mampu menjaga hubungan manusia dengan Tuhan yang diwujudkan dengan mengaplikasikan ajaran-ajaran Agama yang dianutnya sehingga manusia mampu menyadari hakikat dirinya adalah sama di mata Tuhan.
Kesadaran akan dirinya muncul, maka dia akan mampu menjaga hubungan yang harmonis anatara manusia dengan manusia lainnya serta mampu menjaga hubungan yang harmonis antara manusia dengan alam sekitarnya. Kesejahteraan dan kesuburan hidup manusia adalah merupakan wujud nyata dari keharmonisan konsep Tri Hita Karana. Pementasan Jro Gede Panembahan Sakti adalah simbol kemakmuran bagi masayrakat di Desa Gubug, aspek-aspek religius pementasan Jro Gede Panembahan Sakti merupakan sebuah persembahan rasa seni yang memiliki nilai sakral. Implikasi nilai religius dalam Pementasan Jro Gede Panembahan Sakti bagi masyarakat di Desa Gubug merupakan wujud bhakti kepada Ida Sang Hyang Widhi Wasa. Pementasan Jro Gede Panembahan Sakti diyakini dapat mendatangkan keselamatan dan ketenangan bhatin. Tingkat pemahaman dan keyakinan terhadap ajaran Agama bisa dicapai apabila terjadi keselarasan pemahaman antara unsur tattwa, etika dan ritual. Pelaksanaan kegiatan Agama didalam kehidupan sehari-hari ketiga kerangka dasar Agama Hindu ini tetap dijadikan sebagai pedoman, demikian halnya dengan pementasan Jro Gede Panembahan Sakti yang merupakan tarian sakral yang memiliki nilai religius yang kuat.

\section{SIMPULAN}

Berdasarkan penjelasan terkait mengenai pelaksanaan pementasan Jro Gede Panembahan Sakti di Desa Gubug Kecamatan Tabanan Kabupaten Tabanan (Persfektif Komunikasi Transendental) sebagai berikut:

1. Setiap kegiatan upacara yajna dan tradisi bagi umat Hindu di Bali memiliki proses sebagai suatu kesatuan yang mampu memberikan gambaran tentang sarana, tempat dan waktu suatu tradisi itu dilaksanakan.Pementasan Jro Gede Panembahan Sakti di Desa Gubug Kecamatan Tabanan juga memiliki prosesi atau sesuai dengan kepercayaan umat Hindu di Desa Gubug, proses pelaksaaan pementasan Jro 
Gede Panembahan Sakti dilaksanakan beberapa tahapan yaitu : Waktu dan tempat pelaksanaan, dimana pementasan Jro Gede Panembahan Sakti di Desa Gubug ini dilaksanakan pada saat pelaksanaan piodalan di Pura Panembahaan Sakti Dalem Majapahit yaitu pada hari Saniscara kliwon wuku Kuningan tepatnya pada saat Hari Raya Kuningan, tahap awal persiapan pelaksanaan Pementasan Jro Gede Panembahan Sakti didahului dengan Nedunan Ida Bhatara Jro Gede Panembahan Sakti yang berupa barong landung yang ada di Pura Panembahan Sakti Dalem Majapahit. Sebelum Ida Bhatara Jro Gede Panembahan Sakti dipentaskan dalam upacara piodalan, terlebih dahulu memasang prerai (kepala) karena preraidan badan Jro Gede Panembahan Sakti diletakkan secara terpisah. Setelah prerai Ida Bhatara Jro Gede Panembahan Sakti selesai dipasang, pemangkumenghaturkan upacara pebyakaonan, prayascita, pengelemijian, penyepuhan, dan upacara ayaban kehadapan Ida Bhatara Jro Gede Panembahan Sakti, selesai menghaturkan upacara seluruh masyarakat Desa Gubug menghaturkan persembahyangan, tahappelaksanaan diawali dengan pementasan Jro Gede Panembahan Sakti dilaksanakan dengan mengelilingi Desa bersama tiga belas pengiringnya, masyarakat pengemon Ida Bhatara Jro Gede Panembahan Sakti serta diiringi oleh gambelan slodingan, dan terakhir Pementasan Jro Gede Panembahan Sakti dilaksanakan di halaman Pura Panembahan Sakti Dalem Majapahit, pada tahappenutuan, sesuwunan yang berupa Barong Landung tersebut dilepas prerai (kepala) Jro Gede Panembahan Sakti, kemudian dilakukan upacara penyineban

2. Unsur-unsur Komunikasi Yang Terkandung Dalam Pementasan Jro Gede Panembahan Sakti di Desa Gubug, Kecamatan Tabanan, Kabupaten Tabanan yaitu : (1) Komunikator, seluruh masyarakat di Desa Gubug kecamatan Tabanan, Kabupaten Tabanan, (2) Pesan yaitu pemangku dan masyarakat melantunkan mantram pada saat persembahyangan melalui pesan verbal maupun nonverbal, (3) Media yang digunakan dalam pementasan Jro Gede Panembahan Sakti, berupa simbol Jro Gede Panembahan Sakti dan banten yang dihaturkan (4) Komunikan adalah Ida Sang Hyang Widhi Wasa dan sesuwunan yang ada di Pura Panembahan Sakti Dalem Majapahit (5) kilas balik (feedback), ketika pelaksanaan pementasan Jro Gede Panembahan Sakti dilaksanakan, masyarakat merasakan kebahagiaan dan kesejahteraan dalam kehidupannya. (7) Hambatan, dalam mempersiapkan pementasan terkadang ada kesalah pahaman antara masyarakat.

3. Implikasi komunikasi yang ditimbulkan dalam pementasan Jro Gede Panembahan Sakti di Desa Gubug Kecamatan Tabanan Kabupaten Tabanan yaitu : (1) Pengetahuan, (2) Implikasi Tri Hita karana, masyarakat pengamong di Pura Panembahan Sakti Dalem Majapahit mendapat perubahan sikap kearah yang lebih baik dalam menjalin kehidupan sosial masyarakat seperti perubahan sikap untuk saling tolongmenolong dan saling memperdulikan masyarakat disekitar, dan juga kemajuan sikap untuk menjadi peduli dan ingin tahu sejarah yang ditinggalkan oleh leluhur, serta masyarakat pengamong di Pura Panembahan Sakti Dalem Majapahit mendapat perubahan sikap untuk senantiasa tetap menjaga tali persaudaraan, persatuan dan kesatuan dalam menyelesaikan proses pelaksanaan upacara piodalan di Pura Panembahan Sakti Dalem Majapahit, (3) Implikasi Religius, yang terhwujud pada tingkah laku masyarakat di Desa Gubug.

\section{DAFTAR PUSTAKA}

Djelantik, A.A.Made.1999. Estetika Sebuah Pengantar. Bandung : Masyarakat.

Arni, Muhamad.2009. Komunikasi Organisasi. Jakarta : Bumi Aksara.

Abdullah, Irwan.Teori dan Metodelogi Studi Agama Menuju Penelitian Agama yang Konteksual, dalam Pustaka Jurnal Ilmu-Ilmu Budaya, Volume VII No. 1 Februari 2008. 
Denpasar: Yayasan Guna Widya Fakultas Sastra Unud, 2008.

Pemasaran Agrowisata Royal Cocoa sebagai Wisata Edukasi di Banjar Wongaya Beten Mengesta Kecamatan Penebel Kabupaten Tabanan. Jurnal Pariwisata Budaya. Volume 4, Nomer 2.

Sutaryo,2005. Sosiologi Komunikasi. Yogyakarta: Arti Bumi Intaran.

Yunanda, M. 2009. Evaluasi Pendidikan. Jakarta: Balai Pustaka.

https://bali.tribunnews.com/2017/12/15/tera pkan-konsep-wana-kertih-di-hutan-

mangrove-untuk-perubahaniklim?page $=2$.

https://elib.unikom.ac.id/download.php?id=99 247/EfektivitasDanUkuran, https://id.wikipedia.org/wiki/Kukuh, Marga, T abanan

https://ekonomi.kompas.com/read/2018/02/1 5/093533926/survei-nielsenmediadigital-dan-media-konvensionalsaling-melengkapi?page $=$ all 